\title{
Metoda Kanguru pada Perawatan Bayi Berat Lahir Rendah
}

\author{
Saur Lidya Margaretha
}

Metoda kanguru adalah suatu teknologi tepat guna untuk perawatan bayi baru lahir khususnya bayi prematur atau berat badan lahir rendah (BBLR), dengan cara melekatkan kulit bayi ke kulit ibu (skin-to-skin contact). Angka kesakitan dan kematian bayi pada masa neonatal masih tinggi. Berkat kemajuan teknologi, bayi prematur dapat diselamatkan tetapi masih terbatas kegunaannya di rumah sakit negara maju. Untuk negara berkembang yang penghasilan perkapitanya masih rendah fasilitas ini merupakan sesuatu yang langka; kalaupun ada jumlahnya sangat terbatas, dengan kemampuan sumber daya manusia rendah. Hal ini merupakan kendala yang dihadapi dalam mengakses teknologi tersebut. Kehadiran Metoda kanguru yang pertama kali diperkenalkan oleh Dr.Rey dan Martinez dari Bogota (Colombia) pada tahun 1978 memberikan harapan baru khususnya di negara berkembang dengan fasilitas terbatas. World Health Organization telah menganjurkan untuk menggunakan Metoda ini sebagai salah satu alternatif bagi perawatan bayi prematur. Metoda ini dijamin aman dan mampu memenuhi kebutuhan dasar bayi baru lahir berupa kehangatan, ASI, kasih sayang dan perlindungan.

Kata kunci: Metoda kanguru, BBLR, bayi prematur

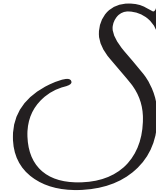

etiap tahun, diperkirakan sekitar 20 juta bayi lahir dengan BBLR. Penyebab BBLR dapat karena lahir sebelum waktunya (prematur) atau gangguan selama masih dalam kandungan. Kejadian BBLR di negara berkembang banyak dihubungkan dengan kemiskinan. Secara statistik angka kesakitan dan kematian pada masa neonatus di negara berkembang cukup tinggi, dengan penyebab utama berkaitan dengan BBLR. ${ }^{1}$ Angka kejadian BBLR di

\footnotetext{
Alamat korespondensi:

Dr. Saur Lidya Margaretha. Bagian Ilmu Kesehatan Anak Fakultas Kedokteran Universitas Sumatera Utara/ RSUP H.Adam Malik Jl. Bunga Lau no.17 Medan. Tel (061) 8361721 - 8365663 Fax. (061) 8361721 E-mail : bikafkusu@telkom.net; kotak Pos 697 Medan - 20136
}

Indonesia masih tinggi, berkisar antara 14\%-25\%. ${ }^{2}$ Salah satu penyebab kesakitan dan kematian pada BBLR adalah hipotermia yang dapat menimbulkan komplikasi berupa infeksi, gagal ginjal, serangan apne, perdarahan hebat yang berakhir dengan kematian bayi. ${ }^{3,4}$

Di Indonesia lebih dari $60 \%$ ibu yang melahirkan di rumah ditolong oleh dukun bayi atau bidan desa, dengan angka kejadian BBLR sebesar $14 \%{ }^{3,4}$ Perawatan BBLR di pedesaan hingga saat ini belum menggunakan fasilitas inkubator dengan peralatan untuk mengatur suhu, kelembaban udara yang baik serta pencegahan terhadap infeksi. Tidak semua bayi dapat memperoleh pelayanan kesehatan dengan teknologi maju karena hambatan biaya, geografis, transportasi dan komunikasi. Oleh karena itu diperlukan cara alternatif yang efektif dan ekonomis sebagai pengganti inkubator. Pada saat ini 
sedang dikembangkan perawatan bayi secara kanguru yang di Indonesia masih dalam tahap penelitian. $^{5}$

Metoda kanguru (MK) atau yang disebut kontak kulit ke kulit, pertama kali dikembangkan oleh Rey di Bogota, Kolombia, tahun 1978; kemudian dilanjutkan oleh Martinez dan Navarette. ${ }^{6,8,10} \mathrm{Hal}$ ini dilakukan untuk mengatasi kelangkaan fasilitas dan sumber daya rumah sakit untuk merawat BBLR. ${ }^{6,8,11,12}$ Sejak akhir 1980-an MK dikembangkan oleh Colombian Department of Social Security and World Laboratory sebuah lembaga swadaya berbasis masyarakat di Swiss. Negara-negara berkembang sangat dianjurkan mengadopsi metoda ini, mengingat terbatasnya fasilitas pelayanan kesehatan, terutama di daerah pedesaan. ${ }^{6}$ Rumah Sakit Umum Pusat (RSUP) Dr. Sardjito Yogyakarta, menjadi rumah sakit pertama di Indonesia yang mengembangkan tehnik merawat bayi ala kanguru yang diberi nama Perawatan Bayi Lekat (PBL). ${ }^{13}$ Sedangkan Alisjabana A dkk, melakukan satu pilot studi di RS. Hasan Sadikin (RSHS) Bandung. Bayi BBLR yang dilahirkan dan dipulangkan dari rumah sakit dibagi menjadi kelompok kontrol dan kelompok intervensi dengan MK, ternyata pada kelompok intervensi kenaikan berat badan, kestabilan suhu tubuh dan pemberian ASI lebih baik dibanding kelompok kontrol. Dari studi ini dikeluarkan direkomendasikan agar MK diterapkan dengan melihat kebiasaan yang berbeda di Indonesia. ${ }^{3}$ Perkumpulan Perinatologi Indonesia (Perinasia) dan Unit penelitian Kesehatan FK-UNPAD serta DepKes melakukan studi penerimaan MK pada wanita pedesaan di Ogan Komering Ulu (OKU), propinsi Sumatera Selatan dan implementasinya di kabupaten Deli Serdang, propinsi Sumatera Utara dan kabupaten Maros, propinsi Sulawesi Selatan. Hasil memperlihatkan bahwa pada umumnya wanita pedesaan menerima MK karena dianggap sesuatu yang relatif baru. Ibu BBLR pengguna MK juga berpendapat bahwa MK menyebabkan bayi lebih tenang, banyak tidur dan banyak menetek. Umumnya mereka mempraktekkan MK selama 28 hari dan dilakukan kurang dari 5 jam per hari. Untuk tiap wilayah tertentu dikenal istilah lokal yang berkaitan dengan MK misalnya "bedako" di Kabupaten.OKU, "makaleppe" (bahasa Makasar) dan "kadukui" (bahasa Bugis). Studi ini menyimpulkan bahwa MK layak diterapkan dan umumnya diterima oleh wanita pedesaan untuk merawat BBLR secara mudah dan murah (tepat guna). ${ }^{10}$

\section{Kapan metoda kanguru ini bisa dimulai ?}

Metoda kanguru (MK) bisa dimulai apabila ibu dan bayi sudah merasa cukup sehat. Pada bayi normal MK bisa dimulai segera setelah pemotongan dan perawatan tali pusat. Bayi didekapkan kepada ibu untuk mencegah hipotermi dan juga merupakan rangsangan produksi ASI. Bagi BBLR/bayi prematur yang tanpa masalah sebenarnya MK bisa dilakukan segera setelah lahir. Mengingat BBLR khususnya prematur seringkali dihadapkan dengan berbagai komplikasi serius seperti asfiksia, sindrom distres respiratory, infeksi dan masalah pemberian minum; maka MK sebaiknya ditunda sampai kondisi bayi stabil (suhu tubuh stabil, nafas teratur, koordinasi mengisapmenelan dan bernafas baik). Jadi saat yang tepat untuk memulai MK bersifat individual tergantung umur kehamilan, berat lahir, umur pasca natal, berat penyakit yang diderita bayi, dan kondisi ibu. ${ }^{1,14,15}$ Berdasarkan kriteria tersebut, Anderson ${ }^{16}$ membagi menjadi 4 kategori.

I. Late kangaroo care, dimulai setelah bayi melalui fase perawatan intensif. Pernafasan sudah stabil dan bernafas spontan. Perawatan dimulai beberapa hari atau minggu setelah lahir. ${ }^{11,16}$

II. Intermediate kangaroo care, dimulai setelah bayi melalui perawatan intensif sekitar 7 hari setelah lahir. Bayi-bayi ini dapat tetap mendapat terapi oksigen karena kadang-kadang apne dan bradikardi. Bayi dengan ventilator yang belum stabil juga termasuk dalam grup ini. ${ }^{11,16}$

III. Early kangaroo care, dilakukan pada bayi yang sudah stabil dan MK dimulai sesegera mungkin setelah kondisi bayi stabil. Metoda kanguru dapat dilakukan pada hari pertama ataupun 1 sampai 6 jam pertama setelah lahir. ${ }^{11,16}$

IV. Very early kangaroo care, dimulai saat bayi diberikan pada ibunya pada menit pertama sampai 90 menit pertama setelah lahir. ${ }^{11,14,16}$ Di rumah sakit yang perlengkapan perawatan BBLR tidak ada untuk periode stabilisasi awal, ${ }^{14}$ ibu yang melahirkan dengan posisi semi jongkok yang disokong, didudukkan dengan kaki yang menyilang, angkat bayinya dan pelukkan. Jika ibu melahirkan dengan 
posisi berbaring, bayi ditempatkan telungkup dekat dengan payudaranya. ${ }^{16}$

\section{Lama penggunaan metoda kanguru.}

Lama bayi dalam posisi kanguru bila mungkin dua puluh empat jam terus menerus. ${ }^{1,17-19}$ Apabila ibu tidak sempat, tugas sementara diganti oleh orang lain (suami, nenek, bibi atau anggota keluarga yang lain). Bayi yang dirawat di neonatal intensive care unit (NICU), MK dilakukan secara bertahap misalnya selama satu jam (agar tidak mengganggu waktu istirahat bayi) sebelum terus menerus selama 24 jam. ${ }^{1}$

Metoda ini dihentikan atau tidak dipakai apabila bayi sudah tidak menghendaki lagi yaitu umur kehamilan ibu sekitar 37 minggu atau berat badan bayi 2500 gram. Pada usia tersebut pada umumnya bayi mulai gelisah atau rewel kalau diletakkan pada posisi kanguru. ${ }^{1,20}$

Metoda kanguru terdiri dari 4 komponen penting.

1. Posisi kanguru (kangaroo position), yaitu kontak kulit ke kulit antara ibu dan bayi yang diberikan selang seling atau terus menerus dan dapat dimulai segera atau ditunda. ${ }^{8,11,15,21}$ Dengan tujuan untuk beradaptasi dengan lingkungan di luar uterus, diletakkan di dada ibu dan dapat menyusu. ${ }^{6}$

2. Nutrisi (kangaroo nutrition), yaitu pemberian ASI eksklusif dan mendapat suplemen hanya dengan formula pengganti untuk bayi prematur jika penambahan berat badan tidak tercapai. ${ }^{6,11,15,22}$

3. Dukungan kanguru (kangaroo support), yaitu pada waktu antenatal ibu perlu diberikan informasi mengenai MK ini, sehingga ibu lebih siap untuk metoda ini apabila bayi lahir dengan berat badan rendah/premature. Dukungan dalam bentuk dukungan emosi, fisik dan pendidikan. ${ }^{22}$

4. Kepulangan dan pemantauan (kangaroo discharge), yaitu ibu tetap melakukan kontak kulit ke kulit terus menerus, dilakukan di rumah sehingga bayi dalam keadaan dan berkembang dengan baik. ${ }^{6,11,15,22}$ Dipantau setiap hari sampai berat badan bertambah paling sedikit $20 \mathrm{gr} /$ hari. $^{1,6,20}$

\section{Persyaratan yang diperlukan untuk metoda kanguru.}

Dua persyaratan yang diperlukan dalam penerapan $\mathrm{MK}^{20}$

1. Kesiapan ibu dan bayi: secara fisik dan mental ibu telah sanggup dan bayi telah melewati masa krisis.

2. Kesiapan institusi, menyangkut baik secara nasional maupun lokal dan didukung tenaga yang mempunyai ketrampilan. ${ }^{20}$

\section{Metoda kanguru dilakukan pada tiga keadaan yang berbeda}

1. Pada rumah sakit dengan fasilitas perawatan neonatal tidak tersedia, perawatan dengan metoda kanguru hanya dilakukan sebagai alternatif bila kekurangan inkubator atau jumlah perawat terbatas. ${ }^{6,11,23}$

2. Pada tempat perawatan neonatal dengan standar yang baik tetapi kurang dapat menguasai cara perawatan. Metoda kanguru digunakan sebagai salah satu alternatif pengganti pada metoda konvensional. ${ }^{6,11}$

3. Pada unit neonatal yang mudah digunakan pada semua tingkat fasilitas layanan, metoda kanguru digunakan untuk memperbaiki ikatan batin antara ibu-bayi dan untuk mendapatkan ASI. ${ }^{6,11}$

\section{Posisi dan perawatan metoda kanguru (PMK) ${ }^{1}$}

1. Saat ibu berdiri atau duduk, posisi bayi tegak/ vertikal mendekap ibu, kepalanya miring ke kiri

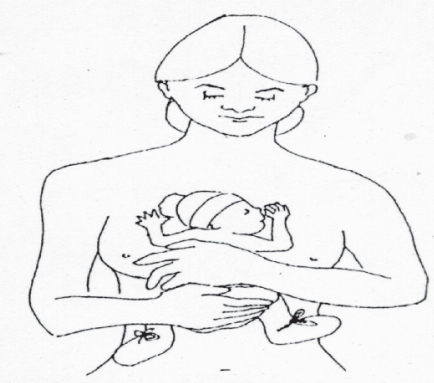

Gambar 1. Memposisikan bayi untuk PMK

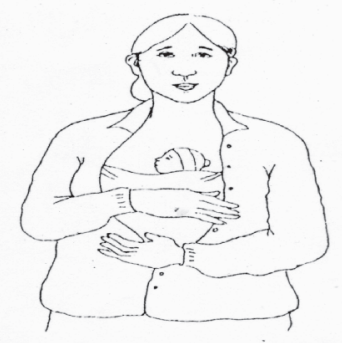

Gambar 2. Bayi dalam posisi PMK 


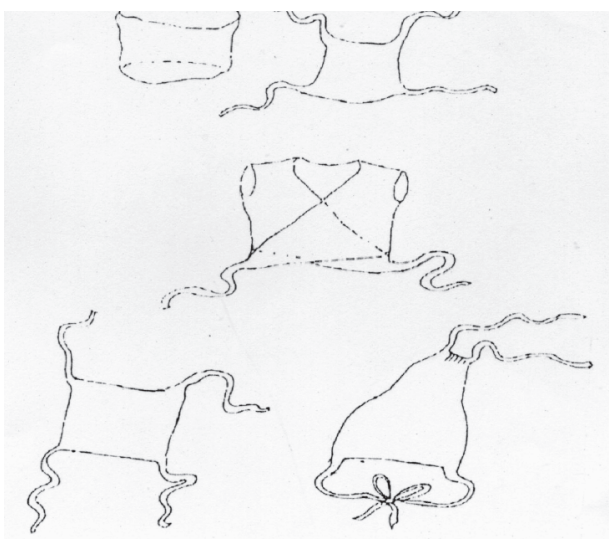

Gambar 3. Kantong untuk menggendong bayi PMK

atau kanan, untuk mencegah risiko regurgitasi dan aspirasi. ${ }^{2,23,24}$ Bayi diletakkan di antara payudara $i b u^{1,22-24}$ di dalam baju, gaun panjang dengan ikat pinggang ${ }^{1,23}$ atau selimut ${ }^{23,24}$ yang berfungsi seperti kantong kanguru. ${ }^{22}$

2. Bila ibu berbaring, posisi bayi tengkurap miring mendekap ibu, kepala miring ke kiri atau kanan. Pada posisi ibu miring kepala bayi miring sesuai dengan arah miring ibu, lalu keduanya diselimuti secara penuh kecuali bagian kepala.,

3. Sebelum bayi dimasukkan ke dalam baju kanguru, bayi harus diberi tutup kepala/topi dan popok. ${ }^{1,4,22-24}$

4. Bayi dimasukkan dalam keadaan telanjang ke dalam baju kanguru. Bagian bawah baju diikat dengan simpul hidup. ${ }^{1,4,22-24}$

5. Bayi dijaga terus menerus pada posisi yang sama oleh ibu atau ayah atau anggota keluarga yang lain. ${ }^{1,22}$

\section{Manfaat metoda kanguru}

Perawatan MK adalah suatu metoda perawatan BBLR yang diilhami oleh seekor kanguru merawat anaknya yang selalu lahir prematur. Sebelum metoda ini diperkenalkan semua bayi dengan berat kurang dari 1000gr meninggal, sekarang $1 / 3$ dari bayi-bayi ini dapat diselamatkan. ${ }^{7}$ Berbagai penelitian mengenai MK telah dilakukan baik di negara berkembang maupun negara maju, dan didapatkan beberapa keuntungan menggunakan MK dibandingkan perawatan bayi secara tradisional (menggunakan inkubator). ${ }^{1,7,8,17}$

1. Pemberian ASI

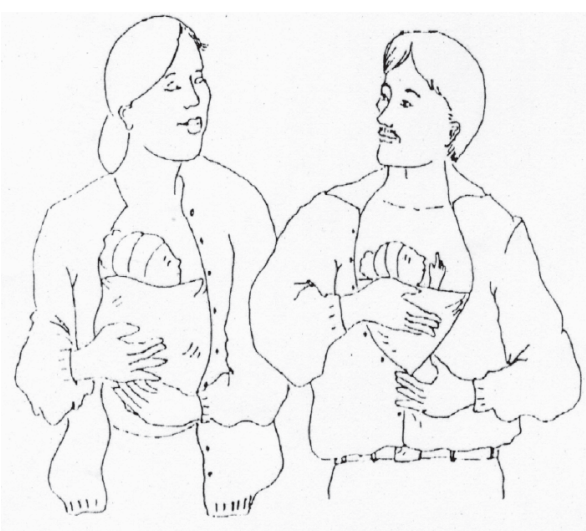

Gambar 4. Mendekap bayi ke dada

Pemisahan ibu-bayi dan teknologi yang digunakan pada unit neonatal membuat ikatan yang sulit dan menciptakan halangan untuk mendapatkan ASI. Perawatan cara kanguru yang diberikan oleh ibu yang dimulai dalam beberapa jam setelah kelahiran menstimulasi produksi ASI dan tentu saja meningkatkan ikatan antara ibu dan bayi. ${ }^{1,3,7}$ Beberapa penelitian mengenai efek MK pada pemberian ASI menunjukkan bahwa, pemberian ASI menjadi lama, produksi ASI lebih stabil, jumlah pemberian ASI perhari meningkat, keyakinan untuk memberikan ASI meningkat banyak dan kebanyakan bayi prematur pulang dengan ASI eksklusif. ${ }^{6,11,16}$

2. Kepercayaan ibu dan ikatan emosional Perawatan MK meningkatkan tingkat kepercayaan dan kecakapan ibu, terutama ketika MK dimulai segera satu atau dua hari setelah lahir. Ibu menyukai kontak kulit ke kulit karena hal ini memberikan peluang untuk lebih dekat dengan bayinya dan perasaan lebih tentram dan menyenangkan. Dalam situasi penuh stres seperti lamanya perawatan bayi, ibu yang melakukan MK merasa lebih percaya diri, terampil merawat bayi yang sangat kecil, dibanding dengan ibu yang menggunakan metoda konvensional.,11,14,16 Affonso dkk, ${ }^{25}$ mewawancara 66 ibu bayi prematur (800-2300 gram) di Helsingborg, Swedia; 33 ibu dengan MK memberikan reaksi secara emosional pada bayinya, cenderung lebih percaya dalam memberikan ASI dan ingin sekali cepat pulang dibanding dengan grup kontrol (inkubator). $7,16,23$

3. Sepsis

Tidak ada satupun laporan tentang penggunaan 
MK yang mengatakan adanya peningkatan terjadinya sepsis. ${ }^{7,16} \mathrm{Hal}$ ini tampaknya disebabkan flora normal kulit ibu lebih aman bagi bayi prematur yang mendapat ASI dari pada organisme yang resisten terhadap antibiotik yang terdapat di rumah sakit. ${ }^{7}$ Sloan $\mathrm{dkk},{ }^{26}$ menemukan penurunan yang bermakna dari infeksi berat seperti pneumonia dan sepsis pada kelompok MK dibanding dengan kelompok inkubator.

4. Hemat biaya

Perawatan dengan MK dapat mengurangi/ menghemat biaya perawatan. ${ }^{20}$ Sloan dkk, menemukan pengurangan biaya perawatan yang bermakna selama MK, karena hari rawat di rumah sakit menjadi jauh berkurang. ${ }^{11,20,26}$

\section{Pengaruh perawatan metoda kanguru}

1. Temperatur, suhu tubuh ibu merupakan sumber panas yang efisien dan murah, dapat memberikan lingkungan hangat pada bayi. Suhu tubuh ibu yang konstan lebih aman dibanding risiko hipotermi dan hipertermi yang dapat dialami bayi pada penggunaan inkubator dengan pengelolaan yang kurang baik. ${ }^{3}$ Acoleth $\mathrm{dkk},{ }^{27}$ yang mencatat secara serial temperatur kulit pada tiga orang dengan berat badan bayi 1000 gram, 1100 gram, dan 1250 gram, pada sebelum, selama dan sesudah kontak kulit ke kulit menunjukkan temperatur kulit terpelihara dengan baik. ${ }^{7}$ Selama perawatan kanguru ibu menunjukkan thermal synchrony dengan bayinya yaitu suhu tubuh ibu meningkat atau menurun sesuai kebutuhan untuk memelihara bayinya dalam batas suhu yang netral $\left(36,5-37,5^{\circ} \mathrm{C}\right) .^{4,16,20}$

2. Oksigenasi, pernafasan lebih teratur maka frekuensi episode apne berkurang. Pada penelitian mengenai respirasi dan saturasi oksigen pada polygraph setelah periode 8 jam ditemukan apne dan saturasi oksigen hampir sama pada bayi kanguru ataupun inkubator. ${ }^{7,20}$

3. Denyut jantung, Ludington $\mathrm{dkk}^{28}$ menemukan bahwa frekuensi jantung, frekuensi pernafasan, saturasi oksigen dan temperatur kulit tetap dalam batas normal untuk kedua grup (kanguru dan inkubator) pada semua periode.

4. Waktu menangis, Alisjahbana dkk, ${ }^{3}$ dari penelitiannya mendapatkan bahwa jumlah menangis menurun secara bermakna pada bayi prematur dibandingkan dengan grup kontrol (inkubator). Gray dkk, ${ }^{29}$ mendapatkan bahwa kontak kulit ke kulit sebagai analgetik pada bayi sehat yang dilakukan pemeriksaan darah dan ternyata tangisan dan wajah berkerut menurun masing-masing $82 \%$ dan $65 \% .^{29,30}$

5. Waktu tidur, jumlah waktu tidur bayi dengan MK lebih lama dibandingkan bayi dalam inkubator. ${ }^{14}$ Suradi dkk, ${ }^{10}$ melaporkan 116 ibu-ibu yang berada di pedesaan menyambut positif keuntungan merawat dengan cara kanguru, 92,7\% menyatakan bahwa bayi mereka tidur lebih banyak, 90\% bayi mereka lebih tenang.

6. Berat badan, Bayi dalam perawatan MK tumbuh sedikit lebih baik dari bayi yang dirawat dalam inkubator. $^{14}$

\section{Implementasi dari metoda kanguru}

Tanpa memperhatikan tingkat fasilitas perawatan neonatal yang diperoleh, keberhasilan MK tergantung dari pendidikan yang meliputi banyak hal dari petugas kesehatan yang profesional, kemauan orang tua, kontak kulit ke kulit, pemberian nutrisi, fasilitas rumah sakit untuk ibunya, pemantauan setelah pulang. ${ }^{11}$

\section{Ringkasan}

Perawatan metoda kanguru (MK) merupakan salah satu tehnologi tepat guna yang sederhana, murah dan dapat digunakan ketika fasilitas untuk perawatan BBLR sangat terbatas. Keuntungan menggunakan MK antara lain kebanyakan bayi kanguru mendapatkan ASI eksklusif oleh karena produksi ASI lebih stabil, meningkatkan hubungan ibu dengan bayi, menurunkan kejadian infeksi dan mempersingkat masa rawat di rumah sakit sehingga dapat menghemat biaya. Sampai saat ini tidak ada dilaporkan kerugian dalam menggunakan MK. Untuk itu diperlukan upaya yang lebih strategis untuk mempopulerkan metoda yang sangat bermanfaat ini.

\section{Daftar Pustaka}

1. World Health Organization. Thermal protection of the new born: a practical guide. Geneva: World Health Organization; 2003. 
2. Ramelan S. Kematian neonatal dini dalam hubungannya dengan berat lahir dan masa gestasi. Jakarta: Departemen Ilmu Kesehatan Anak Fakultas Kedokteran Universitas Indonesia, 1989. Tesis.

3. Alisjahbana A, Usman A, Irawati S, Triyati A. Prevention of hypothermia of low birth infants using kangaroo method. Pediatr Indones 1998; 38: 205-14

4. Aldy D. Manfaat methode kangguru pada perawatan bayi berat lahir rendah. Dalam: Hamid ED, Tobing LTC, Situmeang R, penyunting. Bebas polio tahun 2000 dan penatalaksanaan bayi berat lahir rendah. Naskah lengkap Pendidikan Berkelanjutan Ilmu Kesehatan Anak. Medan: FK-USU, 1997.h.68-76.

5. Monintja HE. Beberapa aspek kebutuhan bayi kurang bulan. Dalam: Suradi R, Monitja HE, Amalia P, Kusumowardhani D, penyunting. Penanganan mutakhir bayi prematur. Naskah lengkap Pendidikan Kedokteran Berkelanjutan Ilmu Kesehatan Anak XXXVIII. Jakarta: Balai Penerbit FK-UI, 1997. h.11-43.

6. Tessier R, Cristo M, Velez S, Giron M, de Calume ZF, Ruiz-Palaez JG, dkk. Kangaroo mother care and the bonding hypothesis. Pediatrics 1998; 102: 1-8.

7. Whitelaw A. Kangaroo baby care: just a nice experience or an important advance for preterm infants? Pediatrics 1990; 85: 604-5.

8. Charpak N, Ruiz-Pelaez JG, Figueroa Z, Charpak Y. Kangaroo mother versus traditional care for new born infants $=2000$ grams: a randomized, controlled trial. Pediatrics 1997; 100: 683-8.

9. Garcia MI. Health-Colombia: Preemies benefit from 'Kangaroo Mother Care'. Didapat dari: URL: http:// www.comeunity.com/premature/baby/kangaroo.html

10. Suradi R, Chair I, Thaha RM. Acceptance of the kangaroo care method by mothers in rural area. Pediatr Indones 1998; 38: 215-23.

11. Kirsten GF, Bregman NJ, Hann FM. The management of breast feeding: Kangaroo mother care in the nursery. Pediatr Clin North America 2001; 48: 1-10.

12. Bohnhorst B, Heyne T, Peter CS, Poets CF. Skin-to skin (kangaroo) care, respiratory control, and thermoregulation. J Pediatrics 2001; 138: 193-7.

13. Hardiastuti W, Yusmili Y. Merawat bayi ala kangguru. GAMMA 2001; 32-3

14. World Health Organization. Thermal protection of the new born: a practical guide. WHO/FHE/MSM/ 97.2

15. Djelantik IGG. Esensi metode kanguru dalam perawatan bayi premature / BBLR. Perawatan Metode Kanguru bagi bayi berat lahir rendah. Prosiding KONAS PERINASIA
: 3-4 Oktober; Medan, Sumatera Utara; 2003.

16. Anderson GC. Current knoeledge about skin to skin (kangaroo) care for preterm infants. J.Perinatol 1991; 11: 216-26.

17. Charpak N, Ruiz-Pelaez JG, Charpak Y. Rey-Martinez kangaroo mother program: an alternative way of caring for low birth weight infants? One year mortality in two cohort study. Pediatrics 1994; 94: 804-10.

18. Charpak N, Figueroa de Colume Z, Ruiz JG . The Bogota declaration on kangaroo mother care conclusions at the second international workshop on the method. Prosiding dari Second International Workshop on kangaroo mother care; Bogota,Colombia; 1998.

19. Neonatology special features. Kangaroo mother care. Didapat dari: URL: http://www.pps.org.ph/neo_feat.asp

20. Djelantik IGG.Perawatan bayi baru lahir dengan metoda kanguru (kangaroo program care). Prosiding KONAS PERINASIA : 3-4 Oktober; Medan, Sumatera Utara; 2003.

21. Conde-Agudelo A, Diaz-Rossello JL, Belizan JM. Kangaroo mother care to reduce morbidity and mortality in low birthweight infants. Juli 2000 Didapat dari: URL:_http:// www.nichd.nih.gov/Cochranelconde-agudelo/review.htm

22. Mudiyanse R M. Kangaroo care. Birth research news letter 1998. Didapat dari: URL:_http://www.naresa.ac.lk/ other/birth/b091998.htm

23. Whitelaw A, Sleath K. Myth of marsupial mother: Home care of very low birth weight babies in Bogota, Colombia.Lancet 1985; I: 1206-8.

24. Brietbach K. What is kangaroo care? Pediatric Nursing Division University of Iowa Hospital \& Clinics.Mei 1993. Didapat dari: URL: http://www.vh.org/pediatricl patient/pediatrics/kanga/-10k

25. Affonso DD, Wahlberg V, Persson B. Exploration of mothers reactions to the kangaroo method of prematurity care. Neonatal Network 1989;7:43-51.

26. Sloan NL, Camacho LWL, Rojos EP, et all. Kangaroo mother method: randomised controlled trial of an alternative method of care for stabilized low birth weight infants. Lancet 1994; 344: 782-5.

27. Acoleth D, Sleath K, Whitelaw A. Oxygenation, heart rate and temperature in very low birth weight infants during skin to skin contact with their mothers. Acta Paediatr Scand 1989; 78:189-193.

28. Ludington Hoe SM, Hashemi MS, Argote LA, Medellin G, Rey H. Selected physiologic measures and behavior during paternal skin contact with Colombian infants. J Dev Physiol 1992; 18: 223-32.

29. Gray L, Watt L, Blass EM. Skin to skin contact is analgesic in healthy newborn. Pediatrics 2000; 105:1-13. 
Sari Pediatri, Vol. 8, No. 3, Desember 2006

30. Christensen K, Baht GJ, Amadi BC, Eriksson B, Hojer B. Randomised study of skin to skin versus incubator care for rewarming low-risk hypothermic neonates. Lancet 1998; 352: 1115 